\title{
Reducing Multidimensional Poverty of Elderly: The Role of the New Rural Pension Scheme in China
}

\author{
Yaqian Hu $\mathbb{D}^{1}{ }^{1}$ Hao Han $\left(\mathbb{D},{ }^{2}\right.$ and Pei Liu $\mathbb{D}^{3}$ \\ ${ }^{1}$ School of Insurance and Economics, University of International Business and Economics, Beijing 10029, China \\ ${ }^{2}$ New China Life Insurance Company Ltd., Beijing 100029, China \\ ${ }^{3}$ School of Economics and Management, Zhejiang Normal University, Jinhua 321004, China \\ Correspondence should be addressed to Pei Liu; liupei0106@zjnu.edu.cn
}

Received 20 November 2021; Accepted 20 December 2021; Published 29 January 2022

Academic Editor: Daqing Gong

Copyright (C) 2022 Yaqian Hu et al. This is an open access article distributed under the Creative Commons Attribution License, which permits unrestricted use, distribution, and reproduction in any medium, provided the original work is properly cited.

Poverty is a multidimensional concept. Besides income, it also includes many nonmonetary dimensions, such as education, health, housing, and access to public goods. Applying a nationally representative survey dataset, this study mainly investigates the role of China's New Rural Pension Scheme (NRPS) in reducing multidimensional poverty among the rural elderly. We first select four dimensions of life quality, health, social inclusion, and subjective welfare to construct multidimensional poverty indicators. We then divide the sample into two parts by age (45-59 and above 60) and evaluate the poverty-reduction effects of participating behaviors and receiving behavior separately. Moreover, we use the insured subsample to investigate the dynamic influence from insured status on received status. The results showed that, for the 45-59 age group, NRPS participation helped reduce poverty across the given indicators, especially in terms of health, life, and subjective welfare. For the elderly (over 60), receiving the pension effectively reduced poverty. In addition, we found that as age increases, pension income can effectively alleviate the insured subgroup's multidimensional experience of poverty.

\section{Introduction}

At the end of 2020, China announced that it had completely eliminated absolute poverty, which was a great achievement in human history. Despite China's great progress in alleviating poverty, China still faces significant work to address the issues of an aging society, especially poverty among its elderly citizens. By the end of 2020, China's population aged 60 and over had reached 264 million, accounting for $18.7 \%$ of the total population, while those aged 65 and over reached 190 million, accounting for 13.5\% (Source: National Bureau of Statistics of the People's Republic of China). Proportionally, more of these poor and elderly people live in rural China than in urban areas [1]. The incidence rate of poverty in 2015 among China's elderly (aged $60+$ ) was 15.2\%, with the rural elderly accounting for $19.7 \%$ of the elderly facing poverty (Source: China health and retirement report, Research Group of China Health and Retirement Longitudinal Study (CHARLS) of Peking University, 2019 revision). As such, mitigating poverty among the rural elderly is a crucial aspect of general poverty alleviation in China.

The New Rural Pension Scheme (NRPS) was a major initiative taken by the Chinese government to solve the poverty problem of the elderly in rural areas in 2009. Since the implementation of NRPS, many literatures have studied its policy effects. Overall, most studies affirmed its effect on improving the welfare of rural elderly. For example, Liu et al. [2] found that the NRSP significantly improved the quality of life of rural elders. Zhang et al. [3] found that NRPS income decreased the probability of being food poor and vulnerability to food poverty among elderly with chronic diseases by $12.9 \%$ and $16.8 \%$, respectively. Nevertheless, some studies have suggested that the poverty-reduction effect of pension insurance is insufficient. Tao [4], for example, found that the NRPS does not adequately protect the rural elderly.

However, it is worth noting that poverty is not just manifested in a certain dimension such as income or 
consumption; it is a multidimensional concept. On the one hand, elderly poverty includes economic poverty, which manifests as having meager or no income and relying entirely on government or family for livelihood, or as a decline in consumption since the proportion of basic living expenses is too high. However, poverty also exists in terms of living standards and mental and physical health. Such poverty can include unclean drinking water, inadequate sanitation facilities, difficulties with housing, increased risk of illness, insufficient recreational activity and social participation, and dissatisfaction with life [5-8]. All of these are common in rural China, and according to Sen's [9] theory of capability, they are all manifestations of poverty. Therefore, when assessing the poverty-reduction effect of social security, it is also important to consider dimensions that are not strictly economic, such as quality of life, health, and subjective welfare, that is, multidimensional poverty. However, in the existing research, less attention has been paid to the policy effect of the NRPS on multidimensional poverty. Therefore, this article focuses on the evaluation of the effects of the NRPS on the inspection of multidimensional poverty. Besides, there are also some shortcomings in the existing research on multidimensional poverty, such as a single choice of dimensions, which is also the problem that this article wants to solve.

This study aims to investigate whether the NRPS has effectively solved the multidimensional poverty of the rural elderly. Its main innovations are as follows: (1) in addition to considering traditional life quality and health dimensions, we considered social inclusion (e.g., relationships with children and neighbors) and subjective welfare (e.g., life satisfaction), which reflect the living conditions of the elderly in their social networks of rural acquaintances. (2) The poverty-reduction effect of the NRPS was decomposed into the poverty-reduction effects of participating behavior and receiving behaviors, and the effects for people aged 45-59 and those over 60 were examined separately. (3) For the insured subsample, the dynamic influence from insured status to received status was further investigated.

The rest of this paper is organized as follows: Section 2 lists the policy background of the NRPS and literature review. Section 3 describes the data and methodology used in this paper, including the construction of multidimensional poverty indicators for the elderly in rural China. The research model and the analysis of the results are presented in Section 4. Robustness checks and conclusions are provided in Sections 5 and 6, respectively.

\section{Literature Review}

Pensions, children, and financial assets are all tools to guarantee income for the elderly [10]. Previous foreign studies have confirmed that pensions can reduce the incidence of poverty among the elderly. House et al. [11] suggested that social security can significantly improve the living conditions of the elderly and reduce the likelihood of poverty. Zimmer and Kwong [12] found that social security reduced the incidence of poverty among the elderly and compensated for a lack of economic support from children.
Bertranou et al. [13] found that, in Latin America, social pensions played an important role in reducing elderly poverty. Kakwani and Subbarao [14] suggested that while general social pensions are not effective for reducing poverty, social pensions targeting the elderly poor do reduce poverty. This view is supported by a number of other studies [15-18].

Due to the comparatively low level of pensions of the NRPS, its poverty-reduction effect is somewhat controversial, but in general, most studies have confirmed its positive impact. Lu et al. [19] found that social welfare programs reduced poverty rates by approximately 32\%. Many studies supported that the NRPS significantly improved the quality of life of rural elders [20] and increased the expected food expenditure amongst the elderly [21]. Not only the NRPS improved the quality of material life, but also it was found that NRPS improved the health status of the elderly. Cheng et al. found that NRPS participation positively affected the physical health, cognitive functioning, and psychological well-being of the rural elderly and reduced mortality over a three-year period by six percentage points [22]. Wand and Zheng found that pension income improves mental wellbeing by relieving depression of the rural elderly; however, the beneficial effects of pension income are extremely limited [23]. However, some research results are not optimistic. For example, Ning et al. found that the introduction of the NRPS program does not improve the welfare effect of the originally targeted elder individuals with illness [24]. Despite being controversial, the results of most of the literatures overall affirmed the welfare improvement effect of the NRPS. In view of the current inconsistent research conclusions, we are more curious about whether the NRPS can improve the multidimensional poverty of the rural elderly.

As for multidimensional poverty, the most important concern for multidimensional poverty is to determine the dimensions and indicators for measurement. Sen [9] suggested that poverty refers to not only low income, but also the deprivation of people's basic capabilities. Individual welfare cannot be measured using just one dimension such as income or consumption; rather, it needs to be examined in terms of multiple dimensions of feasible capabilities. As people grow older, their capabilities will vary, and their composition of welfare will change. George and Bearon [25] argued that elderly welfare comprises four dimensions: general health and functional status, socioeconomic status, life satisfaction, and self-esteem. Lawton [26], meanwhile, proposed the dimensions of behavioral skills (measured by the cognitive dimensions of health and social behavior), perceived life quality, mental welfare (including personal judgments of mental health and life satisfaction), and the objective environment (e.g., housing, economic index). Brandtstädter and Greve [27] defined elderly welfare as a dynamic equilibrium process of assimilating balance, adapting to the environment, and self-selecting to achieve a realistic sense of self. Johnson and Smeeding [28] used income, health status, and social-security effectiveness to measure elderly poverty. Using the Freedom Poverty Measure, Callander et al. [29] suggested that poverty among 
the elderly should be based on income, health, and education. Praag and Ferrer-I-Carbonell [30] argued that poverty is an individual feeling and not an objective status. Yang et al. [31] recognized that poverty is multidimensional and should develop poverty indicators based on life experiences. Bradshaw and Finch [32] measured multidimensional poverty using the dimensions of income poor, subjective poor, and necessity poor.

In recent years, scholars have noticed the effect of social capital on poverty. Rosas [33] defined an individual's personal social network as the sum of all relationships that the individual considers important, or relationships that are different from anonymous groups in society, such as family, friends, colleagues, classmates, community, and services or beliefs. Wagle [34] believed that families can obtain resources to avoid poverty through social inclusion. Chantarat and Barrett [35] found that social network capital can supplement or replace productive assets to help poor families get rid of poverty. Lahn [36] believed that it is unreasonable to define people with low incomes but good social networks as poverty. Social networks can serve as employment networks to help individuals or families alleviate or even get rid of poverty. The Australian aborigines interviewed also said that they did not feel poor, because they still have family members. Therefore, the poverty of social network should also be included in the concept of multidimensional poverty.

Based on the review of relevant literatures, it was found that the connotation of poverty has been expanded to multiple dimensions, while few studies have focused on the poverty-reduction effect of the NRPS on multidimensional poverty. The measurement of multidimensional poverty is also controversial. Based on this deficiency, this article will first establish a multidimensional poverty measurement system and explore the poverty-reduction effect of the NRPS.

\section{Research Method}

\subsection{Construction of Multidimensional Poverty Indicators and Results}

3.1.1. Indicator Construction. Based on prior research, this study selected the dimensions of life quality, health, social inclusion, and subjective welfare to measure multidimensional poverty among rural elderly in China. Based on the United Nations Millennium Development Goals and the present situation in rural China, the selected life-quality dimension included six indicators: drinking water, sanitation facilities, fuel, housing, lighting, and durable consumer goods. Regarding the health dimension, data from the China Health and Nutrition Survey show that, in middle- and oldage individuals, the incidence rate in the last four weeks continues to increase with age, and the average incidence rate for people over 65 is $27 \%$. Elderly have a high incidence of chronic disease, and their health status is significantly below that of other groups. Increased medical costs cause the elderly to be extremely vulnerable to poverty. Therefore, the health dimension included two indicators of chronic disease and medical insurance. For social inclusion and subjective welfare, we mainly considered the problem of "rural hollowing" in the process of urbanization in China. The China Family Development Report of 2015 indicated that half of China's elderly were "empty-nest," while $10 \%$ lived alone (Source: National Health Commission of the People's Republic of China). The emergence of rural hollowing has tended to reduce family sizes in rural China as younger gene rations move to the city, and the length of separation between parents and offspring has increased, leading to feelings of loneliness and helplessness among the elderly. In addition, this study set the corresponding deprivation threshold (poverty line) based on Alkire and Foster [37]. Table 1 shows the composition of the multidimensional poverty indicators.

3.1.2. Multidimensional Poverty Index Results Based on the A-F Method. The A-F method [37] was used to measure multidimensional poverty. It is obtained using the following steps.

The first step is to assign values for each dimension, determining the value of individual $i$ in all dimensions and the value distributions of different individuals in each dimension.

The second step is poverty identification. Poverty is identified in every dimension. After determining the deprivation threshold for each dimension, the poverty status of individual $i$ in a single dimension is obtained according to whether the value of individual $i$ in the dimension is below the deprivation threshold. Second, multidimensional $(k)$ deprivation is identified. Defining the number of deprived dimensions experienced by individual $i$ as $c_{i}(k)$, when $c_{i}(k) \geq k$, then $q_{i}(k) \geq k=1$; otherwise, $q_{i}(k)=0$. $q_{i}(k)$ indicates whether individual $i$ is poor in $k$ dimensions, which is affected by the deprivation value of a single dimension and deprivation across dimensions. Therefore, it is referred to as a dual cut-off method. When summing up the dimensions, the weights of each dimension must be considered. We assigned a weight to the dimension $j$ equal to the ratio of the number of poor people in $j$ dimension to the number of poor people in all poverty dimensions. Considering the influence of different years, the poverty dimensions will have different values for different years. Since the number of indicators in each dimension is different, we used the equal-weight method to give weight to indicators in the same dimensions.

The third step is to aggregate poverty. After identifying the deprivation of each individual in various dimensions, poverty can be aggregated to obtain a multidimensional poverty index. The multidimensional poverty index and average deprivation share calculation formulas under the A-F method as follows:

$$
\begin{aligned}
\operatorname{MPI}(k) & =\sum_{i=1}^{n} \frac{c_{i}(k)}{(n d)}, \\
A(k) & =\sum_{i=1}^{n} \frac{c_{i}(k)}{\left(\sum_{i=1}^{n} c_{i}(k) d\right)} .
\end{aligned}
$$


TABle 1: Construction of the multidimensional poverty indicator.

\begin{tabular}{|c|c|c|}
\hline Dimension & Indicator & Cut-off value \\
\hline \multirow{6}{*}{$\begin{array}{l}\text { Standard of } \\
\text { living }\end{array}$} & Drinking water & Nontap/bottled water/pure water/filtered water for cooking $=1$; else $=0$ \\
\hline & Toilets & Do not use indoor or outdoor flush toilets or dry toilets $=1$; else $=0$ \\
\hline & Cooking fuel & Use firewood as the main living fuel $=1$; else $=0$ \\
\hline & Housing & Housing difficulties $=1 ;$ else $=0$ \\
\hline & Electricity & No power or frequent power outages $=1$; else $=0$ \\
\hline & Durable goods & $\begin{array}{l}\text { No TV, washing machine, refrigerator (freezer), computer, mobile phone, electric bicycle, } \\
\text { motorcycle, car, any durable goods }=1 \text {; else }=0\end{array}$ \\
\hline \multirow{2}{*}{ Health } & Medical insu & No medical insurance $=1$; else $=0$ \\
\hline & Chronic diseases & Have a chronic disease $=1$; else $=0$ \\
\hline \multirow{2}{*}{ Social inclusion } & $\begin{array}{l}\text { Relationship with } \\
\text { neighborhood }\end{array}$ & Have a bad relationship with neighbors $=1$; else $=0$ \\
\hline & Social status & Self-valued local social status is very low (less than 3 points for \\
\hline \multirow{2}{*}{$\begin{array}{l}\text { Subjective well- } \\
\text { being }\end{array}$} & Future confidence & $\begin{array}{l}\text { Have no confidence in your future (assignment is less than } 3 \text { points, excluding } 3 \text { points) }=1 \text {; } \\
\text { else }=0\end{array}$ \\
\hline & Life satisfaction & Dissatisfied with your own life (less than 3 points, not including 3 points) $=1$; else $=0$ \\
\hline $\begin{array}{l}\text { a source: } \mathrm{CF} \\
\text { fidence, and } \\
\text { atisfied, and }\end{array}$ & $\begin{array}{l}\text { 2014, 2016. Note: } \\
\text { ir life satisfaction. T } \\
\text { ts being very harmo }\end{array}$ & $\begin{array}{l}\text { PS questionnaire asks respondents how close they are to their neighbors, their social status, future } \\
\text { rvey is self-scoring, a score of } 0 \text { represents being very unharmonious/very low/very unconfident/very } \\
\text { /very high/very confident/very satisfied. (2) The } 2016 \text { questionnaire only asked about the three quality of } \\
\text { onsumer goods. This paper defines at least one of the indicators of poverty as a significant reduction in }\end{array}$ \\
\hline
\end{tabular}

Here, $n$ represents the number of individuals, $d$ represents the overall dimension of measuring poverty, and $H(k)=\sum_{i=1}^{n} q_{i}(k) / n$ represents the incidence rate of poverty. It can be seen that MPI $=H \times A$; that is, the multidimensional poverty index is obtained by adjusting the incidence of poverty through the average deprivation share.

3.2. Data and Variables. The data came from the 2012, 2014, and 2016 waves of the China Family Panel Survey (CFPS). The CFPS is a nationwide social follow-up survey conducted by the China Social Science Survey Center of Peking University. It aims to collect three levels of data-individual, family, and community-to reflect changes in society, economy, population, education, and health in China. The survey sample covers 25 provinces (municipalities or autonomous regions), and the target sample size is 16,000 households. The survey object includes all family members in the sample households. After the national baseline survey was conducted in 2010, a regular biennial full-sample tracking survey was conducted.

To assess the poverty-reduction effect of the NRPS, we differentiated the poverty-reduction effect into a participation effect and a receiving effect. For the participation effect, the research object was people aged 45 to 59. After excluding individuals who had participated in or received other pensions and deleting cases of missing values for key variables, we obtained a three-year pooled cross-section sample of 15,076 individuals (5,210 individuals in 2012, 5,203 in 2014 and 4,663 in 2016). For the receiving effect, the research object was the rural elderly aged 60 and over. We obtained a three-year pooled cross-section sample of 11,456 individuals (3,325 individuals in $2012,3,815$ in 2014, and 4,316 in 2016).
The explanatory variables in this study were obtained based on the multidimensional poverty measures of the rural elderly in China, as we defined above. The equal-weight method [38] was adopted to define life-quality poverty (lifepoverty), health poverty (healthpoverty), social-inclusion poverty (socialpoverty), and subjective-welfare poverty (swell-beingpoverty) of the elderly. If more than half of the indicators in each dimension are in a state of poverty, elderly subject $i$ is defined as poor in dimension $j$, with a value of 1 , otherwise 0 . Then, using the ratio of the number of poor people in the $j$ dimension to the number of poor people in all poverty dimensions as the weight, the weighted deprivation score of each elderly person is obtained through the nonequal weight method. When the weighted deprivation score of the elderly person is greater than 0.33 , the individual is considered experiencing multidimensional poverty [38]; a dummy variable (multipoverty) equal to 1 is defined; otherwise, it equals 0 .

The main explanatory variable is the NRPS variable. Based on the characteristics of the NRPS policy, we examined the poverty-reduction effects of participating and receiving behaviors. For the participation effect, we defined a dummy variable (participation) representing whether one participates in the insurance scheme. For the receiving effect, we defined a dummy variable (pension) representing whether one receives pension income and a variable representing the annual pension income amount (pension_amount). At the same time, considering that the poverty-reduction effect of the NRPS policy may have a certain time lag, we also defined a variable representing the years since they began participating in the NRPS (part_time) and a variable representing the years since they began receiving NRPS income (pen_tim), to further evaluate the effect of poverty-reduction via the participation 
and receiving behaviors. We also controlled personal characteristic variables, family characteristic variables, and village and regional characteristic variables. Table 2 shows the variable selection and definitions.

As shown in Table 2, in the insured sample, on average, $67.19 \%$ of 45 to 59 -year-old rural people participated in the NRPS. The enrollment rate was $59 \%$ in $2012,70.7 \%$ in 2014 , and $72.3 \%$ in 2016 (results by year are not listed for reasons of space), indicating that coverage has increased rapidly in rural China. In the receiving sample, on average, $66.75 \%$ of the rural elderly over age 60 received an NRPS income, indicating that most rural elderly are in receipt of this type of social security. Each person received an average of 1,216 yuan per year, showing steady increases year by year (an average of 612 yuan per person per year in 2012, 1,202 yuan in 2014, and 1,694 yuan in 2016), suggesting that the rural elderly have received effective guarantees (The NRPS policy stipulates that the minimum standards for basic pensions will be adjusted in a timely manner according to economic development and price changes, and the standards are not uniform across regions. When the policy was implemented in 2009, the minimum standard for basic pensions was 55 yuan per person per month, which has now been increased to 88 yuan. In addition to personal account pensions, the current national average monthly pension per person is 122 yuan).

Table 3 reports the multidimensional poverty situation of the rural elderly. It indicates that the incidence of multidimensional poverty among people aged $45-59$ was $22.38 \%$, while among the uninsured samples it was $25.88 \%$. The results for health poverty, social-inclusion poverty, and subjective-welfare poverty also showed that the incidence of poverty among insured groups was lower than that of uninsured groups.

Among those over 60, the incidence of multidimensional poverty, health poverty, social-inclusion poverty, and subjective-welfare poverty was lower among those who had received the NRPS pensions. Furthermore, the mean $t$-test showed that the difference in the incidence of poverty between the two groups (participated, not-participated; received, not-received) was significant. It is worth noting that there was no significant difference in life poverty between the insured and uninsured samples and between the receiving and nonreceiving samples.

3.3. Methodology. To study the poverty-reduction effect of the NRPS, we set the following probit model:

$$
\operatorname{Pr}(\text { poverty }=1)=\Phi\left(\alpha_{1}+\beta_{1} \mathrm{NRPS}_{i}+\gamma_{1} X_{i}+\gamma_{2} X_{v}+\mu_{p}+\lambda_{t}\right) \text {. }
$$

Among them, poverty is a dummy variable indicating whether the elderly person is poor. In the probit regression, multipoverty, lifepoverty, healthpoverty, socialpoverty, and swell-beingpoverty were used in turn as the dependent variables. NRPS represents the NRPS variables listed in Table 2. The control variables include elderly's personal characteristics (e.g., age, gender, marital status, education level), family characteristics (e.g., family population, children, and per capita net income), village characteristics (e.g., incidence of natural disasters, landform features, distance from town, and county), and unobservable province and period effects.

It should be noted that because the elderly participate in the NRPS voluntarily, there may be a problem with selfselection. To solve the potential endogeneity problem as much as possible, we used the instrumental variable (IV) method to estimate the participation behavior variables, and we used the county level of the NRPS participation rate (cpart_ratio) as the instrumental variable. An effective IV should satisfy the following two conditions: first, it is highly related to the endogenous explanatory variable; and second, the IV is not related to the error term, which means that the IV is strictly exogenous. The participation rate at the regional level reflects the popularity of the NRPS in various regions. Due to information sharing, social networking, and other reasons, the regional participation rate is highly related to the individual-insured possibility. At the same time, the regional participation rate is not directly related to the disturbance term in the model, which meets the exogenous requirements of IV. Therefore, the county level of the NRPS participation rate (excluding the sample individuals) was selected as IV.

\section{Results}

4.1. Analysis of the Full Sample. For people aged 45-59, we used three waves of pooled cross-section data to estimate the poverty-reduction effect of participation behavior. Table 4 shows the results.

The estimated coefficients of the participation variables in Table 4 show that participating in the NRPS was significantly associated with reduced multidimensional poverty, life poverty, health poverty, and subjective-welfare poverty. Participation in the NRPS thus indicates that people have received old-age security and expect to receive pension income in the future. The expected-income effect makes people feel more secure about the future and thus improves their life satisfaction. Especially for those who are dissatisfied with their current living conditions, such a future guarantee can provide a boost. NRPS participation might also increase the likelihood of participating in medical insurance, which helps reduce the likelihood of falling into health poverty. However, the results in Table 4 also show that NRPS participation did not significantly reduce social-inclusion poverty.

When the date for receiving pensions becomes closer, the expected-income effect may become more apparent. Therefore, we further examined the effect of the duration of insurance coverage on the multidimensional poverty of the middle-aged groups. Table 4 shows that the duration of insurance not only significantly reduced multidimensional poverty, life-quality poverty, health poverty, and subjectivewelfare poverty, but also significantly reduced social-inclusion poverty. These results suggest that participating in the NRPS has effectively reduced the incidence of multidimensional poverty among the rural elderly and effectively alleviated their multidimensional poverty. 
TABLE 2: Variables definitions and descriptive statistics.

\begin{tabular}{|c|c|c|c|c|}
\hline Category & Variables & Definitions & $\begin{array}{l}\text { Participating sample mean } \\
\text { (standard error) }\end{array}$ & $\begin{array}{l}\text { Receiving sample mean } \\
\text { (standard error) }\end{array}$ \\
\hline \multirow{6}{*}{ NRPS variables } & Participation & $\begin{array}{c}\text { Dummy: participating in NRPS }=1 ; \\
\text { else }=0\end{array}$ & $0.6719(0.47)$ & - \\
\hline & Pension & $\begin{array}{c}\text { Dummy: receive NRPS income }=1 ; \\
\text { else }=0\end{array}$ & - & $0.6675(0.47)$ \\
\hline & Pension_amount & Annual amount received (yuan) & - & $1216.86(3242)$ \\
\hline & Part_time & $\begin{array}{c}\text { Years since participating in the NRPS } \\
\text { (only } 2012 \text { data) }\end{array}$ & $2.3745(0.91)$ & - \\
\hline & Pen_time & $\begin{array}{c}\text { Years since receiving the NRPS income } \\
\text { (only } 2012 \text { data) }\end{array}$ & - & $2.0685(0.82)$ \\
\hline & Age & Age & $51.42(4.32)$ & $67.81(6.70)$ \\
\hline \multirow{3}{*}{ Personal variables } & Gender & Dummy: male $=1$; else $=0$ & $0.4864(0.49)$ & $0.4842(0.49)$ \\
\hline & Marriage & Dummy: has a spouse $=1$; else $=0$ & $0.9374(0.24)$ & $0.7664(0.42)$ \\
\hline & Educ & Education, $1-5$, illiteracy $=1$, college $=5$ & $2.1690(0.98)$ & $1.6033(0.79)$ \\
\hline \multirow{6}{*}{ Family variables } & Medical_fee & Education, $1-5$, illiteracy $=1$, college $=5$ & $2247.31(8610)$ & $3197.94(29289)$ \\
\hline & Familysize & Family population & $4.4361(1.89)$ & $4.1946(2.20)$ \\
\hline & Child_num & Family population & $1.6376(0.95)$ & $0.9561(0.84)$ \\
\hline & Fincome_per & $\begin{array}{c}\text { Family annual per capita net income } \\
\text { (yuan) }\end{array}$ & $12109.08(25131)$ & $9748.43(49628)$ \\
\hline & Ftransfer_per & $\begin{array}{c}\text { Family annual per capita transfer } \\
\text { income (yuan) }\end{array}$ & $628.31(4122)$ & 740.4905 (2176) \\
\hline & Land & Dummy: has land $=1$; else $=0$ & $0.6299(0.48)$ & $0.6320(0.48)$ \\
\hline \multirow{5}{*}{ Village variables } & Disaster & $\begin{array}{c}\text { Dummy: the village is a frequent area of } \\
\text { natural disaster }=1 \text {; else }=0\end{array}$ & $0.3692(0.48)$ & $0.3592(0.48)$ \\
\hline & Landforms & Village landform & $2.9830(1.18)$ & $3.0814(1.83)$ \\
\hline & Distance_town & $\begin{array}{l}\text { Distance between village and nearest } \\
\text { market town }(\mathrm{km})\end{array}$ & $6.0655(2.40)$ & $6.6124(2.76)$ \\
\hline & Distance_county & $\begin{array}{l}\text { Distance between the village and the } \\
\text { county seat }(\mathrm{km})\end{array}$ & $25.2606(20.55)$ & $24.9872(20.15)$ \\
\hline & Distance_capital & $\begin{array}{c}\text { Distance between village and provincial } \\
\text { capital }(\mathrm{km})\end{array}$ & $256.2255(271)$ & $252.4294(281)$ \\
\hline \multirow[t]{2}{*}{$\begin{array}{l}\text { Instrumental } \\
\text { variable (IV) }\end{array}$} & Cpart_ratio & $\begin{array}{l}\text { The county-level participation rate } \\
\text { (excluding the elderly themselves) }\end{array}$ & $0.3718(0.18)$ & $0.3462(0.18)$ \\
\hline & \multicolumn{2}{|c|}{ Observations } & 15076 & 11454 \\
\hline
\end{tabular}

Data source: CFPS 2012, 2014, 2016. Note: (1) We divided the level of education into five categories, represented by 1-5, which were illiteracy, primary school, junior middle school, high school, and college or above, respectively. (2) Landforms of villages were divided into seven categories, which were represented by $1-7$, such as, namely, hills, mountains, plateaus, plains, grasslands, fishing, villages, and others. (3) Variables (family income and transfer income) have been winsorized at the 1st and 99th percentile.

TABLE 3: Descriptive statistics of multidimensional poverty among the elderly in rural China.

\begin{tabular}{lcccc}
\hline Variable & Participation & Nonparticipation & Receiving & Nonreceiving \\
\hline Multipoverty & $0.2238^{* * *}(0.4168)$ & $0.2588(0.4380)$ & $0.2316^{* * *}(0.4218)$ & $0.2872(0.4525)$ \\
Lifepoverty & $0.6404(0.4798)$ & $0.6312(0.4825)$ & $0.6920(0.4617)$ & $0.7049(0.4561)$ \\
Healthpoverty & $0.1964^{* * *}(0.3973)$ & $0.2462(0.4308)$ & $0.2873^{*}(0.4525)$ & $0.3043(0.4601)$ \\
Socialpoverty & $0.1707^{* * *}(0.3762)$ & $0.2111(0.4081)$ & $0.1685^{* * *}(0.3744)$ & $0.2032(0.4024)$ \\
Swell-beingpoverty & $0.1958^{* * *}(0.3968)$ & $0.2618(0.4397)$ & $0.2241^{* * *}(0.4170)$ & $0.2709(0.4445)$ \\
\hline
\end{tabular}

Data source: CFPS2012, 2014, 2016. Note: standard deviations are in parentheses. The symbols ${ }^{*},{ }^{* *}$, and ${ }^{* * *}$ indicate statistical significance at the $10 \%, 5 \%$ and $1 \%$ levels, respectively, and are the results of the mean $t$-test.

In addition, the estimated results for the control variables showed that the older the person, the higher the medical expenses, and the greater the likelihood of falling into poverty. Meanwhile, having a spouse and a high level of education helps reduce the incidence of poverty.

However, participating in the NRPS only reflects an "expected-income effect." While receiving pension income reflects a real increase in income, its poverty-reduction effect may be more significant. We therefore estimated the effect of pension income on the multidimensional poverty of people over 60 . Table 5 shows the results.

Table 5 suggests that receiving NRPS income has a significant effect on poverty-reduction in the four dimensions of poverty. This is different from the behavior of participating in insurance, where we did not find a reduction effect for life-quality poverty and social-inclusion poverty. 


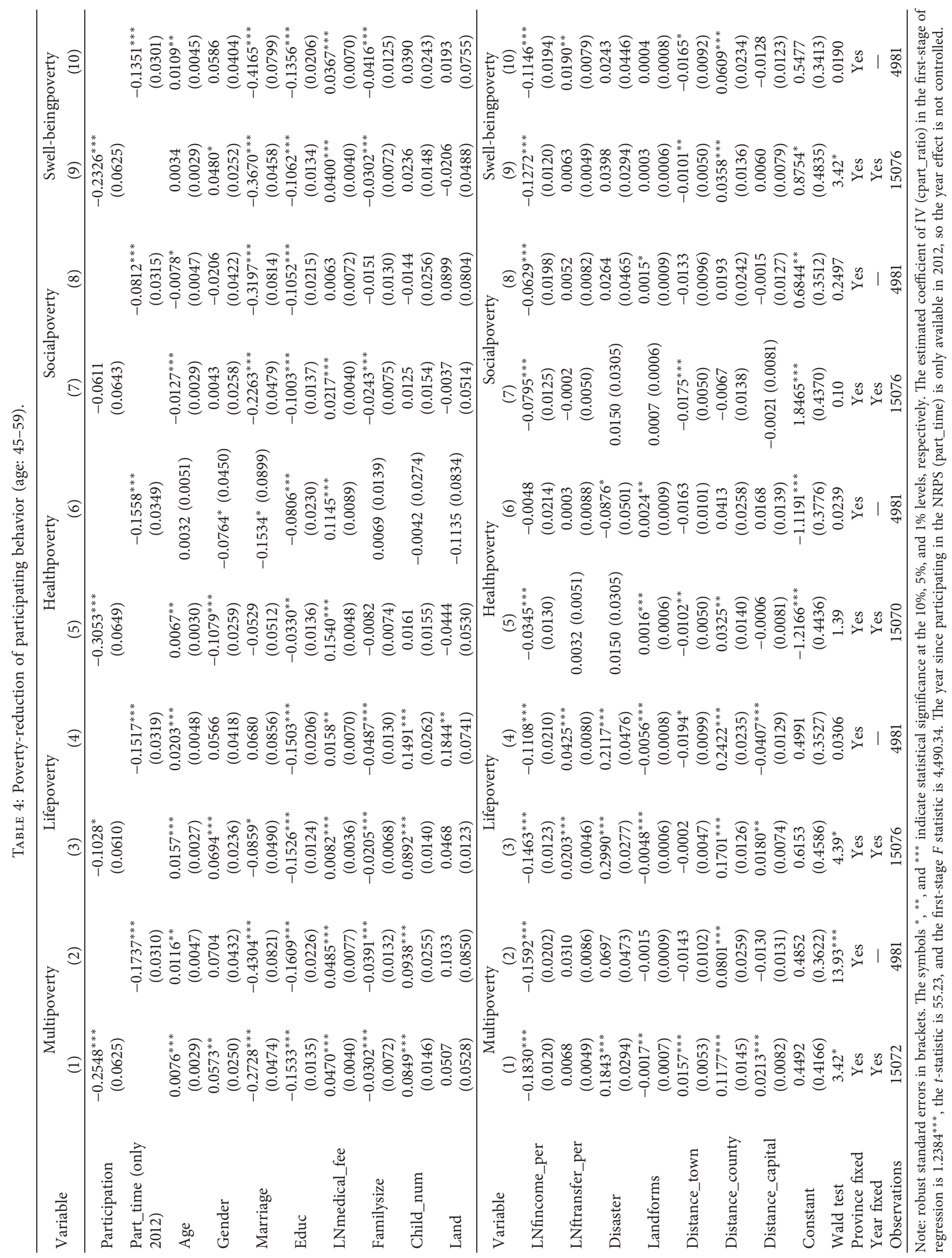




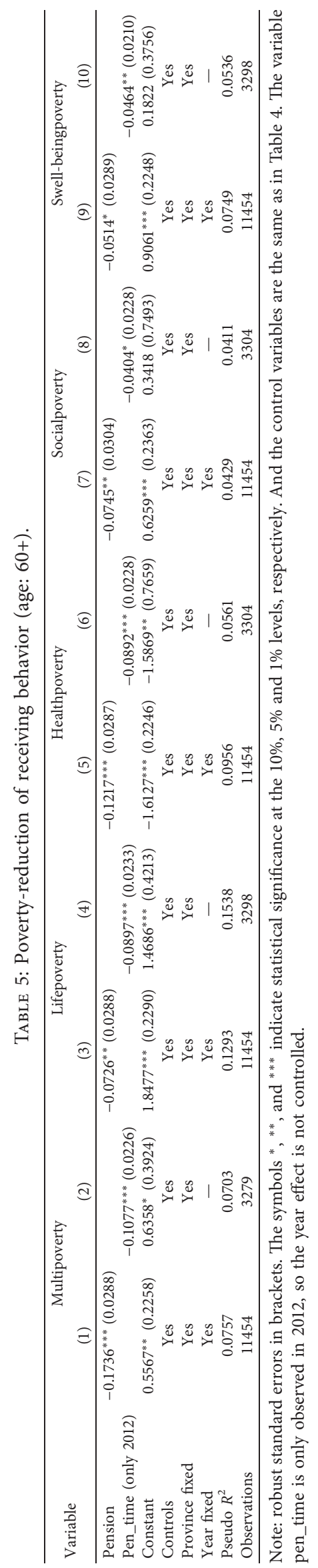


Elderly people in rural China have no steady employment or stable income. As they grow older, their labor capacities decline, and their access to income diminishes, making them more dependent on money transfers from their children and relatives. Although the NRPS income amount is not very large (88 yuan per month), it appears to have significantly helped. Pension income might, for example, improve the elderly's drinking water and sanitation facilities and increase their consumption of durable goods such as televisions and mobile phones, thereby reducing life-quality poverty. The income can also support medical care to some extent, which can improve health and reduce the likelihood of falling into health poverty. Regarding social-inclusion poverty and subjective-welfare poverty, stable pension income can help improve relationships with relatives and friends or increase participation in recreational activities. Therefore, pension income can not only relieve financial concerns, but also reduce feelings of loneliness and thereby improve life satisfaction.

In addition, we used the variable pen_time to examine the poverty-reduction effect of the NRPS. This variable indicates how long the rural elderly have been receiving a pension income. The longer the duration, the more the pension income received, and the more effective it has been. Table 5 shows that it has a significant effect on alleviating multidimensional poverty in four dimensions, which helps further confirm the effectiveness of the NRPS in reducing poverty.

4.2. Analysis of Subsamples. The analysis above shows that both NRPS participation and receiving behaviors can effectively alleviate the multidimensional poverty of the rural elderly. That said, we also wanted to determine whether there is a difference in the effectiveness of poverty-reduction between the two behaviors. After all, participating is an expenditure, whereas receiving produces income; perhaps the two have different individual effects on poverty-reduction. We explored this issue using the insured subsamples. By limiting the sample to those over age 45 who had participated in the NRPS, we could further investigate the poverty-reduction effect of receiving NRPS income. Table 6 reports the results for both the mixed-section data and the panel data.

When the sample was limited to the insured group, neither receiving the pension nor the pension amount (Lpension_amount) reduced multidimensional poverty. Life-quality poverty-reduction was observed only in the mixed-section sample, and poverty-reduction effects in other dimensions were not significant. This result suggests that although insurance participation is represented as an economic expenditure and receiving behavior is represented as income, when we measured its poverty-reduction effect from the perspective of multidimensional poverty, there was no significant difference between the two.

It is worth noting that Table 6 shows that the povertyreduction effect on health poverty is positive and significant, leading us to wonder if this result indicates that the NRPS policy worsens poverty. To explain this result, we introduced the interaction term of age and pension to examine the moderating effect of age on health poverty (see Table 7). The coefficient of introducing age as an interaction term is significantly negative, indicating that there is indeed a negative regulating effect on age; that is, as age increases, the poverty-reduction effect of NRPS on health poverty becomes even greater. In addition, to further explore the reasons for the positive effect of NRPS on health poverty, we divided the samples by age into five groups (we divided the age into five groups: 45-49 years old, 50-54 years old, 55-59 years old, 60-64 years old and 65 years old and above), multiplied the age group by the penalty, and calculated the fitting margin of each group (the average fitted value of the subsamples). Then, we expressed the fitted margin of each group and the corresponding standard error in the form of an interaction effect diagram, as shown in Figure 1 (the horizontal axis of the fitting effect graph is the age group, and the vertical axis is the fitting margin of the corresponding subsamples, i.e., "linear prediction." The blue line represents the estimated results of those who have not received the pension, and the red line represents the estimated results of those who have received the pension). It can be seen that before the blue line crosses the red line (ages 60-65), the average incidence of healthy poverty among recipients is higher than that of the nonreceiving individuals. The decline in average health poverty further confirms the negative regulating effect of age on health poverty. In addition, the coefficient of the interaction term pension_age indicates that the age factor also has a moderating effect on multidimensional poverty and lifequality poverty but no moderating effect on social-inclusion poverty and subjective-welfare poverty.

\subsection{Heterogeneity Analysis of the Poverty-Reduction Effect.} To examine the different effects of NRPS on poverty among different groups, we ran regressions on different subsamples grouped by income, gender, and number of adult children. Table 8 reports the results.

Regarding the poverty-reduction effect of participation behavior (see Panel A, Table 8), it appears that insurance participation can alleviate the life-quality poverty of elderly people who have children, suggesting that, compared to those without children, having adult children can strengthen the poverty-reduction effect of the NRPS. In terms of health poverty, the NRPS can reduce the health poverty of high-income groups. Middle-aged and elderly people with higher incomes are more likely to participate in the New Rural Cooperative Medical Insurance when participating in the NRPS, which is conducive to povertyreduction. However, when grouping elderly people by whether they have an adult child, insurance participation is more effective for reducing the health poverty of those without children. In terms of social-inclusion poverty, consistent with the previous results, insurance participation had no significant effect on reducing poverty. In terms of subjective-welfare poverty, participating behavior had a better effect on poverty-reduction for lowincome elderly people, who were predominantly male and without children. 
TABLe 6: Poverty-reduction effect of insured-subsamples' receiving the NRPS income.

\begin{tabular}{lcccc}
\hline \multirow{2}{*}{ Variable } & \multicolumn{2}{c}{ Pooled cross section data } & \multicolumn{2}{c}{ Panel data sample } \\
& $(1)$ pension & (2) lpension_amount & (3) pension & $(4)$ lpension_amount \\
\hline Multipoverty & $-0.0055(0.0369)$ & $-0.0031(0.0052)$ & $0.0001(0.0135)$ & $-0.0008(0.0019)$ \\
Lifepoverty & $-0.0656^{* *}(0.0313)$ & $-0.0117^{* * *}(0.0043)$ & $-0.0013(0.0134)$ & $-0.0011(0.0019)$ \\
Healthpoverty & $0.1379^{* * *}(0.0332)$ & $0.0162^{* * *}(0.0046)$ & $0.0051(0.0155)$ & $0.0004(0.0022)$ \\
Socialpoverty & $-0.0414(0.0341)$ & $-0.0066(0.0047)$ & $-0.0096(0.0146)$ & $-0.0011(0.0020)$ \\
Swell-beingpoverty & $-0.0262(0.0326)$ & $-0.0038(0.0045)$ & $-0.0150(0.0155)$ & $-0.0018(0.0022)$ \\
Province fixed & Yes & Yes & Yes & Yes \\
Year fixed & Yes & Yes & Yes & 6046 \\
Number of PID & 11609 & 11609 & 14065 & 6046 \\
Observations & 19625 & 19625 & 14065 \\
\hline
\end{tabular}

Note: robust standard errors in brackets. The symbols ${ }^{*},{ }^{* *}$, and ${ }^{* * *}$ indicate statistical significance at the $10 \%, 5 \%$, and $1 \%$ levels, respectively. And the control variables are the same as in Table 4. The FE model uses a sample of at least two-period observations and contains 6,046 individuals (PID).

TABLe 7: Poverty-reduction effect of insured-subsamples' receiving the NRPS income-adding an age interaction term.

\begin{tabular}{lccccc}
\hline Variable & $(1)$ & $(2)$ & $(3)$ & $(4)$ & $(5)$ \\
& Multipoverty & Lifepoverty & Healthpoverty & Socialpoverty & Swell-beingpoverty \\
\hline Pension & $0.002(0.008)$ & $-0.017^{*}(0.010)$ & $0.044^{* * *}(0.009)$ & $-0.010(0.009)$ & $-0.008(0.009)$ \\
Pension_age & $-0.002^{* *}(0.001)$ & $-0.003^{* *}(0.001)$ & $-0.005^{* * *}(0.001)$ & $-0.000(0.001)$ & $0.000(0.001)$ \\
Age & $0.001^{* *}(0.000)$ & $0.003^{* * *}(0.001)$ & $0.002^{* * *}(0.000)$ & $-0.001^{*}(0.000)$ & $-0.000(0.000)$ \\
Controls & Yes & Yes & Yes & Yes & Yes \\
Province fixed & Yes & Yes & Yes & Yes & Yes \\
Year fixed & Yes & Yes & Yes & 19627 & Yes \\
Observations & 19625 & 19625 & 19625 & 19625 \\
\hline
\end{tabular}

Note: robust standard errors in brackets. The symbols ${ }^{*},{ }^{* *}$, and ${ }^{* * *}$ indicate statistical significance at the $10 \%, 5 \%$, and $1 \%$ levels, respectively. And the control variables are the same as in Table 4.

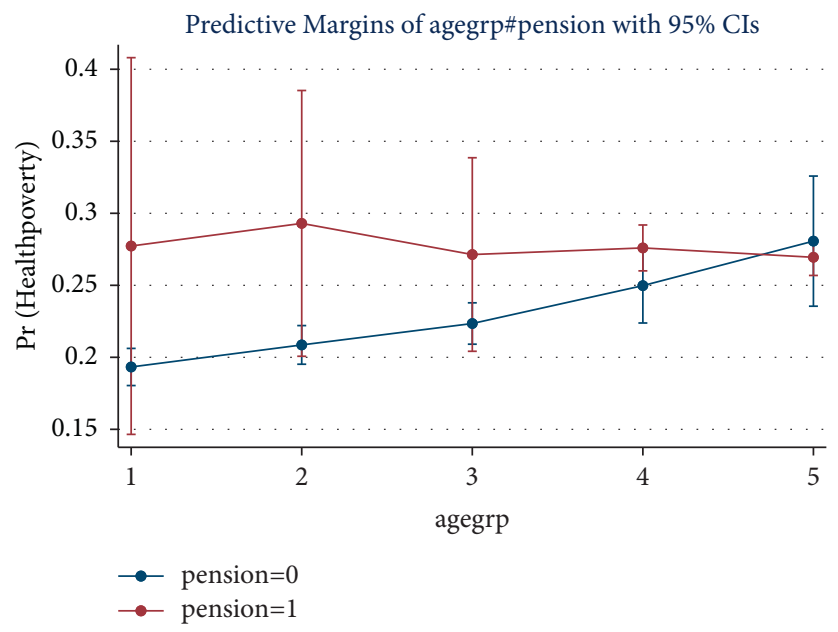

FIGURE 1: Health poverty changes of rural elderly people by age group.

Regarding the poverty-reduction effect of receiving behavior (see panel $\mathrm{B}$, Table 8), it appears that receiving NRPS income can significantly alleviate the life-quality poverty of low-income elderly people, especially men and those who have children. However, it has no significant effect on high-income elderly, especially women who do not have children. For low-income seniors, pension income can mitigate living difficulties and improve life quality. With the help of their children, for example, elderly people are more likely to improve their drinking water and sanitation facilities. It is worth noting that, in terms of social-inclusion poverty, the poverty-reduction effect of NRPS income is mainly reflected in the female and childless elderly groups but has no significant effect on other elderly groups. In rural China, men generally hold financial power. If female seniors can obtain NRPS income, it provides an effective income guarantee, and the right to freely use money will raise their family and neighborhood status and give them more time to participate in social and entertainment activities, which will help reduce social-inclusion poverty. This also applies to the 


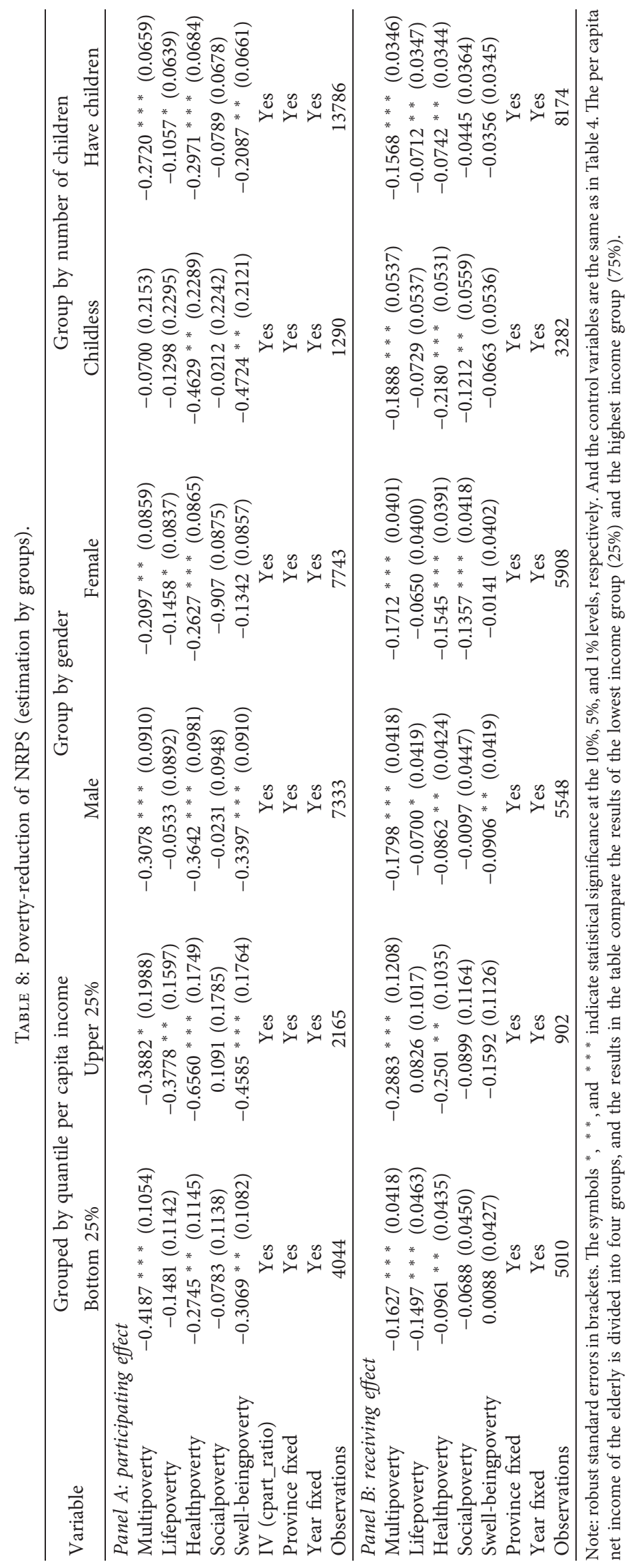




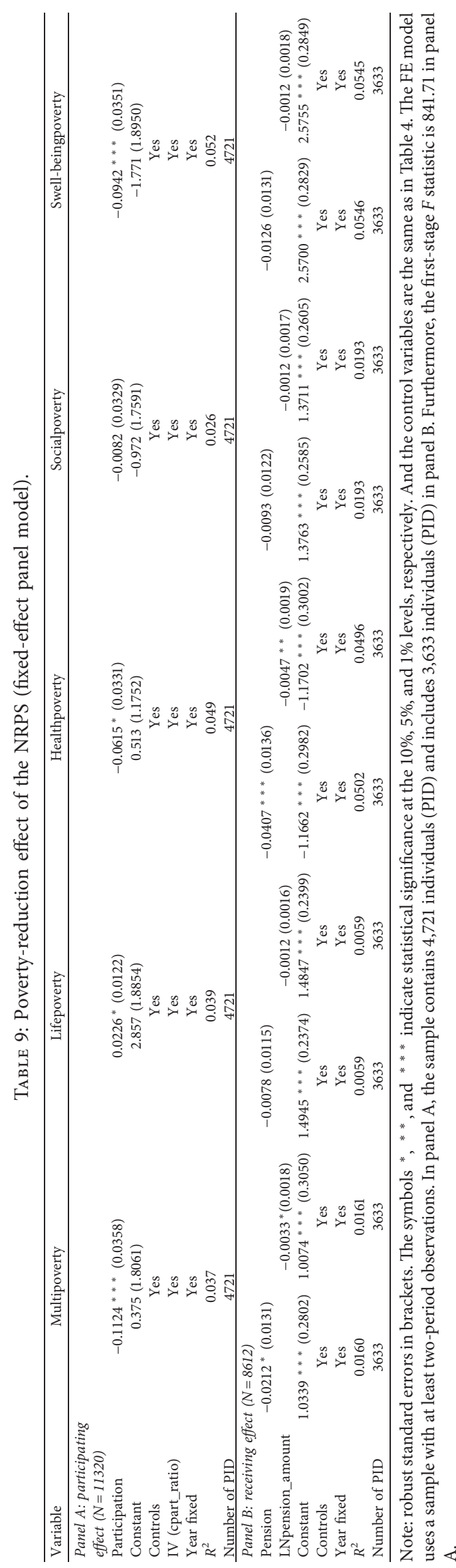




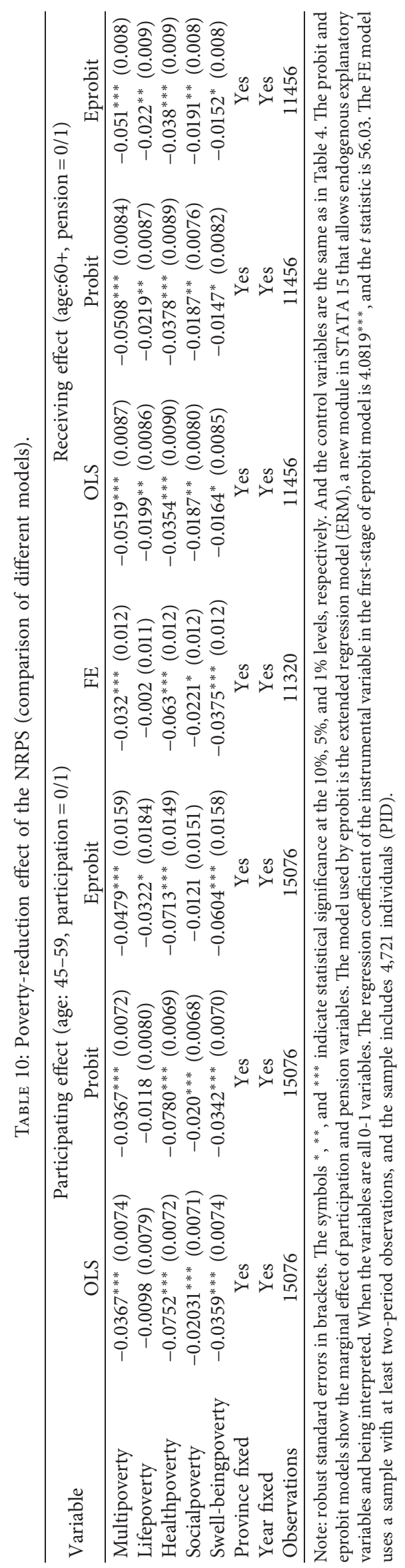


elderly group without children, who rely on pensions to increase their participation in village activities and reduce exhaustion from the difficulties they face in everyday life.

\section{Robustness Check}

We used two methods to test the robustness of the results. The first was to change the data structure. In the previous section, we used pooled cross-section data for estimation. Although we controlled for the year and province effects, the panel data are more effective for solving the problem of missing variables that do not change with time. Therefore, we use a fixed-effect panel model to estimate the povertyreduction effect of NRPS participation and receiving behaviors. The second method was to test the robustness of the results by comparing the results of different models. Below, we list the results of the OLS, probit, E-probit, and FE models without IVs and compare them with the results of the IV method described earlier.

5.1. Panel Estimate Results. We use the fixed-effects panel model to estimate the participation and receiving effects again. The model was set as follows:

$$
\text { poverty }_{i t}=\alpha_{0}+\alpha_{1} \mathrm{NRPS}_{i t}+\sum \alpha_{2} X_{i t}+\sum \alpha_{3} X_{i v t}+\mu_{p}+\lambda_{t}+\varepsilon_{i t} \text {. }
$$

The meanings of variables such as poverty and NRPS are the same as in equation (3). Control variables that do not change over time (e.g., gender, education, village landform features, distance to town, and county) are automatically eliminated in the fixed-effect model. We reconstructed the insured samples and received samples using individuals that included at least two waves of observation. Table 9 lists the results estimated by the FE model.

As shown in panel A, Table 9, when we used the FE model to estimate the poverty-reduction effect of participation again, we found that participating in the NRPS still had a significant negative effect on multidimensional poverty, health poverty, and subjective-welfare poverty among the rural elderly; all were significant at the $1 \%$ level. However, for social-inclusion poverty, participation did not yield any significant effects in poverty-reduction. These results are consistent with those in Table 4. Panel B of Table 9 shows that receiving pension income can have a significant effect on reducing multidimensional poverty and health poverty among the rural elderly, but the effect on reducing other types of poverty was not as obvious. We reestimated the payment variable with the payment amount variable, with consistent results, which is different from the results in Table 5. In Table 5, we find that the rural elderly receiving NRPS income also derive poverty-reduction effects from life-quality poverty, social-inclusion poverty, and subjective-welfare poverty. Overall, however, the results in Table 9 confirm once again that NRPS policy has effectively alleviated the multidimensional poverty of elderly people in rural China.

5.2. Results of Many Different Models. When we no longer consider the endogeneity problem and directly perform the regression, we can compare the results of the benchmark
OLS model with other models to verify the robustness of the results. Table 10 lists the estimation results of the various models. Among them, the coefficient of the probit model represents the marginal utility.

In Table 10, the OLS results for the participation effect show that the coefficient of regression of participation behavior on multidimensional poverty is 0.0367 , which is very close to the coefficients estimated by the probit and FE models. The estimated coefficients of health poverty, socialinclusion poverty, and subjective-welfare poverty are also very similar, and all are significantly negative, further illustrating the robustness of the results. The results for the receiving effect are similar, and the estimated coefficients and significance levels of the various models are also relatively consistent. These comparable results confirm again that the NRPS policy can effectively alleviate the multidimensional poverty of the rural elderly and has played a positive role in reducing overall poverty in rural China.

\section{Conclusions}

This study investigated the effect of NRPS on a multidimensional set of poverty indicators for rural elderly people. First, we constructed the measurement indicators. Then, we used multiple measurement methods to test whether the NRPS has fulfilled its objective to alleviate poverty. Finally, we differentiated the effects of insurance participation and receiving behaviors on reducing poverty of elderly people in rural communities.

Four dimensions (life quality, health, social inclusion, and subjective welfare) were selected to measure multidimensional poverty. Compared to single-dimensional poverty, multidimensional poverty can better reflect the comprehensive nature of poverty and capture deprivation across multiple dimensions. In addition to life quality and health, we also considered social inclusion as a unique dimension of research on poverty, one innovation presented by this study. For the indicators of social inclusion, we selected neighborhood relations, social status, and the number of adult children since these factors comprise the main forms of social capital for China's elderly. Finally, we considered the dimension of subjective welfare, which pertains to people's sense of their own happiness, security, and life satisfaction.

After selecting the four dimensions, data from the CFPS from 2012 to 2016 were used to evaluate the poverty-reduction effect of the NRPS on the rural elderly. For people aged 45-59, NRPS participation was found to reduce multidimensional poverty, mainly reflected in health poverty, life poverty, and subjective-welfare poverty. For those over the age of 60 , receiving NRPS income was found to reduce poverty and showed significant effects on life-quality poverty, health poverty, social inclusion, and subjective welfare. We also examined whether there were any differences in the effect of poverty-reduction between participating by paying into the insurance scheme and receiving income from it. Regression on the insured subsample showed that, for these insured individuals, receiving pensions did not significantly alleviate multidimensional poverty. However, after introducing the interaction terms of age 
and pension variables, the age factor had a moderating effect on dimensions such as multidimensional poverty, lifequality poverty, and health poverty. Essentially, as age increases, pension income can effectively alleviate the insured subgroup's multidimensional experience of poverty. We found, moreover, that the NRPS policy had a more significant poverty-reduction effect on life-quality poverty for low-income elderly, particularly older men with adult children. Furthermore, it more significantly reduced health poverty for elderly people with higher incomes and those without adult children. Lastly, pension income can improve the social inclusion of older rural women, particularly those who do not have adult children.

Along with China's ongoing social and economic development, the pension benefits of the NRPS will gradually increase, and its poverty-reduction effect is expected to become more significant. This can also help China solve the increasingly serious problems inherent to its aging population. For elderly people who remain in rural areas and are left behind when their children migrate to cities, the NRPS system provides not only an effective way to reduce their poverty into old age, but also a means of protection and support.

\section{Data Availability}

The data came from the 2012, 2014, and 2016 waves of the China Family Panel Survey (CFPS). The CFPS is a nationwide social follow-up survey conducted by the China Social Science Survey Center of Peking University, which is open to researchers around the world; more information can be obtained from https://opendata.pku.edu.cn/dataset.xhtml? persistentId=doi:10.18170/DVN/45LCSO.

\section{Conflicts of Interest}

The authors declare that there are no conflicts of interest regarding the publication of this paper.

\section{Acknowledgments}

The study was supported by the National Nature Science Foundation of China (Grant No. 71663049).

\section{References}

[1] S. Chen and M. Ravallion, "Poverty and hunger special feature: absolute poverty measures for the developing world, 1981 2004," Proceedings of the National Academy of Sciences, vol. 104, no. 43, pp. 16757-16762, 2007.

[2] H. Liu, X. Han, Q. Xiao, and S. Li, "Family structure and quality of life of elders in rural China: the role of the new rural social pension," Journal of Aging \& Social Policy, vol. 27, no. 2, pp. 123-138, 2015.

[3] Z. Zhang, Y. Luo, and D. Robinson, "Reducing food poverty and vulnerability among the rural elderly with chronic diseases: the role of the new rural pension scheme in China," International Journal of Environmental Research and Public Health, vol. 15, no. 6, pp. 1253-1273, 2018.
[4] J. Tao, "Can China's new rural social pension insurance adequately protect the elderly in times of population ageing?" Journal of Asian Public Policy, vol. 10, no. 2, pp. 158-166, 2016.

[5] J. Li, "Roles of individual perception in technology adoption at organization level: behavioral model versus TOE framework," Journal of System and Management Sciences, vol. 10, no. 3, pp. 97-118, 2020.

[6] P. Cozma, M. Gavrilescu, M. Rosca, L. Apostol, R. Hlihor, and M. Gavrilescu, "Evaluation of human health risks associated with pesticide dietary intake - an overview on quantitative uncertainty analysis," Environmental Engineering and Management Journal, vol. 17, no. 9, pp. 2263-2274, 2018.

[7] E.-D. Comaniţă, C. Ghinea, R. Hlihor, and M. Gavrilescu, "Occurrence of plastic waste in the environment: ecological and health risks," Environmental Engineering and Management Journal, vol. 15, no. 3, pp. 675-687, 2016.

[8] L. Fu and Y. Dong, "Research on internet search data in China's social problems under the background of big data," Journal of Logistics, Informatics and Service Science, vol. 5, no. 2, pp. 55-67, 2018.

[9] A. Sen, Development as Freedom, Oxford University Press, Oxford, England, 1999.

[10] V. Galasso, R. Gatti, and P. Profeta, "Investing for the old age: pensions, children and savings," International Tax and Public Finance, vol. 16, no. 4, pp. 538-559, 2009.

[11] J. S. House, K. R. Landis, and D. Umberson, "social relationships and health," Science, vol. 241, no. 4865, pp. 540-545, 1988.

[12] Z. Zimmer and J. Kwong, "Family size and support of older adults in urban and rural China---Current effects and future implications," Demography, vol. 40, no. 1, pp. 23-44, 2003.

[13] F. M. Bertranou, W. V. Ginneken, and C. Solorio, "The impact of tax-financed pensions on poverty reduction in Latin America: evidence from Argentina, Brazil, Chile, Costa Rica and Uruguay," International Social Security Review, vol. 57, no. 4 , pp. 3-18, 2004.

[14] N. Kakwani and K. Subbarao, "Poverty among the elderly in Sub-Saharan Africa and the role of social pensions," Journal of Development Studies, vol. 43, no. 6, pp. 987-1008, 2007.

[15] A. Barrientos, "What is the impact of non-contributory pensions on poverty? Estimates from Brazil and South Africa," Chronic Poverty Research Centre Working Paper, vol. 33, 2003.

[16] J.-A. Rivera-Marques, S. Morris, Q. Wodon, and C. Siaens, Evaluation of Mexico City's Safety Net for the Elderly, The World Bank, Washington, DC, USA, 2004.

[17] R. Dimova and F. C. Wolff, "Are private transfers poverty and inequality reducing? Household level evidence from Bulgaria," Journal of Comparative Economics, vol. 36, no. 4, pp. 584-598, 2008.

[18] P. Lloyd-Sherlock, A. Barrientos, V. Moller, and J. Saboia, "Pensions, poverty and wellbeing in later life: comparative research from South Africa and Brazil," Journal of Aging Studies, vol. 26, no. 3, pp. 243-252, 2012.

[19] S. Lu, Y. T. Lin, J. H. Vikse, and C. C. Huang, "Effectiveness of social welfare programmes on poverty reduction and income inequality in China," Journal of Asian Public Policy, vol. 6, no. 3, pp. 277-291, 2013.

[20] Z. Zhang, Y. Luo, and D. Robinson, "Do social pensions help people living on the edge? Assessing determinants of vulnerability to food poverty among the rural elderly," European Journal of Development Research, vol. 32, no. 4, pp. 198-219, 2020. 
[21] W. Huang and C. Zhang, "The power of social pensions: evidence from China's new rural pension scheme," American Economic Journal: Applied Economics, vol. 13, no. 2, pp. 179-205, 2021.

[22] L. Cheng, H. Liu, Y. Zhang, and Z. Zhao, "The health implications of social pensions: evidence from China's new rural pension scheme," Journal of Comparative Economics, vol. 46, no. 1, pp. 53-77, 2018.

[23] F. Wang and H. Zheng, "Do public pensions improve mental wellbeing? Evidence from the new rural society pension insurance program," International Journal of Environmental Research and Public Health, vol. 18, no. 5, p. 2391, 2021.

[24] M. Ning, J. Gong, X. Zheng, and J. Zhuang, "does new rural pension scheme decrease elderly labor supply? Evidence from CHARLS," China Economic Review, vol. 41, pp. 315-330, 2016.

[25] L. K. George and L. B. Bearon, Quality of Life in Older Persons: Meaning and Measurement, Human Sciences Press, New York, NY, USA, 1980.

[26] M. P. Lawton, Competence, Environmental Press, and the Adaption of Older People, Springer, New York, NY, USA, 1982.

[27] J. Brandtstädter and W. Greve, "The aging self: stabilizing and protective processes," Developmental Review, vol. 6, no. 3, pp. 52-80, 1994.

[28] D. S. Johnson and T. M. Smeeding, Who Are the Poor Eldery? an Examination Using Alternative Poverty Measures, Center for Retirement Research Working Paper, Boston College, MA, USA, 2000.

[29] E. J. Callander, D. J. Schofield, and R. N. Shrestha, "Multiple disadvantages among older citizens: what a multidimensional measure of poverty can show," Journal of Aging \& Social Policy, vol. 24, no. 4, pp. 368-383, 2012.

[30] B. V. Praag and A. Ferrer-I-Carbonell, "A multi-dimensional approach to subjective poverty," Quantitative Approaches to Multidimensional Poverty Measurement, Palgrave Macmillan, London, UK, 2008.

[31] L. Yang, C. Jiang, X. Ren, R. Walker, J. Xie, and Y. Zhao, "Determining dimensions of poverty applicable in China: a qualitative study in guizhou," Journal of Social Service Research, vol. 47, no. 2, pp. 1-18, 2020.

[32] J. Bradshaw and N. Finch, "Overlaps in dimensions of poverty,” Journal of Social Policy, vol. 32, no. 4, pp. 513-525, 2003.

[33] R. E. Rosas, "Social networks and urban poverty," Development and Society, vol. 30, no. 2, pp. 41-56, 2001.

[34] U. Wagle, "Multidimensional poverty measurement with economic well-being, capability, and social inclusion: a case from kathmandu, Nepal," Journal of Human Development, vol. 6, no. 3, pp. 301-328, 2005.

[35] S. Chantarat and C. B. Barrett, "Social network capital, economic mobility and poverty traps," The Journal of Economic Inequality, vol. 10, no. 3, pp. 299-342, 2012.

[36] J. Lahn, "Poverty, work and social networks: the role of social capital for aboriginal people in urban Australian locales," Urban Policy and Research, vol. 30, no. 3, pp. 293-308, 2012.

[37] S. Alkire and J. Foster, "Counting and multidimensional poverty measurement," Journal of Public Economics, vol. 95, no. 7-8, pp. 476-487, 2011.

[38] S. Alkire and M. E. Santos, Acute Multidimensional Poverty: A New Index for Developing Countries, Oxford Poverty \& Human Development Initiative (OPHI) Working, Oxford, England, 2010. 